\title{
CONTAMINAÇÃO DE ÁGUAS SUBTERRÂNEAS - AVALIAÇÃO DE VULNERABILIDADE EM UMA BACIA HIDROGRÁFICA TRANSFRONTEIRIÇA IBÉRICA
}

\author{
Teresa Albuquerque \\ Instituto Politécnico de Castelo Branco, CIGAR, Portugal \\ teresal@ipcb.pt \\ Margarida Antunes \\ Instituto Politécnico de Castelo Branco, CIGAR, Portugal \\ imantunes@ipcb.pt \\ Fátima Seco \\ Instituto Politécnico de Castelo Branco, Portugal \\ mf.seco@gmail.com
}

\begin{abstract}
RESUMO
A bacia hidrográfica do rio Águeda é uma bacia transfronteiriça, entre Portugal e Espanha, com potenciais fontes de contaminação, destacando-se as mineiras e agrícolas. Para o estudo em análise, foram recolhidas 75 amostras de água georreferenciadas, em maio de 2012, dentro de uma malha previamente estabelecida. Determinaram-se parâmetros fisíco-químicos e teores de sulfato e cálcio, uma vez que são estes os predominantemente associados à contaminação agrícola. Neste trabalho apresentam-se mapas de distribuição geoquímica para o sulfato e o cálcio, utilizando a krigagem gaussiana com transformação inversa, para a identificação espacial das zonas de maior potencial de contaminação agrícola. A avaliação da vulnerabilidade intrínseca foi obtida através do índice DRASTIC Pesticida, apresentando zonas de vulnerabilidade moderada a elevada. A sobreposição dos mapas de distribuição e de vulnerabilidade permitirá a identificação de áreas de maior risco para a contaminação.

Palavras-chave: água subterrânea; geoestatística; krigagem Gaussiana; mapas estimados; índice Drastic
\end{abstract}

\section{Introdução}

A análise de riscos ambientais é um ponto-chave na otimização do planeamento dos recursos naturais, permitindo uma gestão focada na atenuação ou minimização de prejuízos (e.g. Guerreiro e Pereira, 2002; Scribd, 2013).

O presente trabalho, inserido no projeto POCTEP Águeda, tem como principal objetivo, a análise e caracterização espacial das águas subterrâneas da bacia hidrográfica do rio Águeda, nomeadamente a influência das atividades antropogénicas associadas predominantemente à agricultura (Sanchéz et al, 2013).

\section{Avaliação da Vulnerabilidade intrínseca - DRASTIC Pesticida}

A vulnerabilidade intrínseca representa a capacidade natural de um sistema aquífero em receber e transmitir substâncias potencialmente contaminantes, ao longo do tempo. No presente trabalho foi adotado o índice DRASTIC Pesticida (Aller, 1987), uma vez que apresenta o sistema de ponderação mais adequado às variáveis em estudo, com uma melhor resposta em zonas de agricultura intensiva, com recurso à utilização de pesticidas e, ainda, a aplicação de sulfatos.

A metodologia DRASTIC utiliza 7 parâmetros: profundidade do aquífero $(D)$, recarga $(R)$, material do aquífero (A), tipo de solo (S), topografia ( $T$ ), material da zona vadosa (I) e condutividade hidráulica (C). Cada um destes parâmetros é ponderado tendo em consideração a sua influência na propagação e dispersão de poluentes (Aller et al., 1987; Albuquerque et al., 2013). 


\section{Amostragem}

O planeamento da amostragem é um dos passos mais importantes na construção de cartas de variabilidade espacial (ISA, 2013). Na verdade, o desenho dos pontos de recolha, permitiu assegurar uma amostragem estatisticamente sólida (Fig. 1), possibilitando a captação da variabilidade espacial, para os dois atributos em estudo e para diferentes classes de distância. Com esta distribuição é possível recorrer a metodologias geoestatísticas para a construção dos mapas estimados na distribuição de teores (Saito e Goovaerts, 2000).

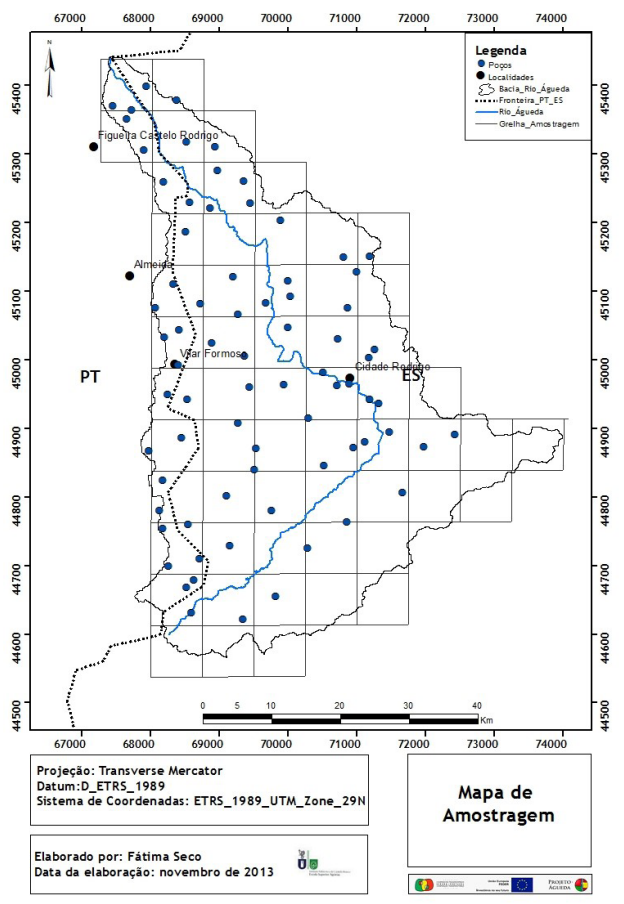

Figura 1. Desenho de amostragem na bacia hidrográfica do rio Águeda.

$\mathrm{Na}$ área em estudo foram selecionadas e recolhidas 75 amostras de água subterrânea (poços), ao longo de uma rede com uma quadrícula equidistante de 7,5 km (Fig. 1). A recolha de amostras decorreu durante o mês de maio de 2012. Em cada um dos 75 pontos selecionados, foram determinados "in situ” os principais parâmetros físico-químicos: oxigénio dissolvido (DO), pH, potencial de oxidação-redução (ORP), condutividade elétrica (CE) e temperatura. Ulteriormente, as amostras de água recolhidas foram acondicionadas e transportadas para os laboratórios do Instituto de Recursos Naturais e Agro-Biologia (IRNASA - CSIC) de Salamanca (Espanha). Neste laboratório foram determinados os teores de cálcio $(\mathrm{Ca})$ e de sulfatos $\left(\mathrm{SO}_{4}{ }^{2-}\right)$. As técnicas analíticas incluíram a cromatografia iónica, absorção atómica.

\section{Metodologia}

A avaliação da vulnerabilidade de um aquífero permite a definição de áreas mais ou menos vulneráveis à contaminação por atividades antropogénicas. A construção de mapas de 
vulnerabilidade constitui uma importante ferramenta de apoio à otimização da exploração de recursos hídricos e, desta forma, no planeamento territorial.

0 índice DRASTIC pesticida foi o adotado, para avaliação da vulnerabilidade intrínseca. A utilização de ferramentas SIG, nomeadamente o recurso ao raster calculator (Arcmap 10, ESRI), permitiu afetar as respetivas ponderações, no subsequente cálculo dos índices finais (Albuquerque et al., 2013).

O mapa obtido ilustra a heterogeneidade de vulnerabilidade à contaminação das águas subterrâneas na bacia hidrográfica do rio Águeda (Fig.2).

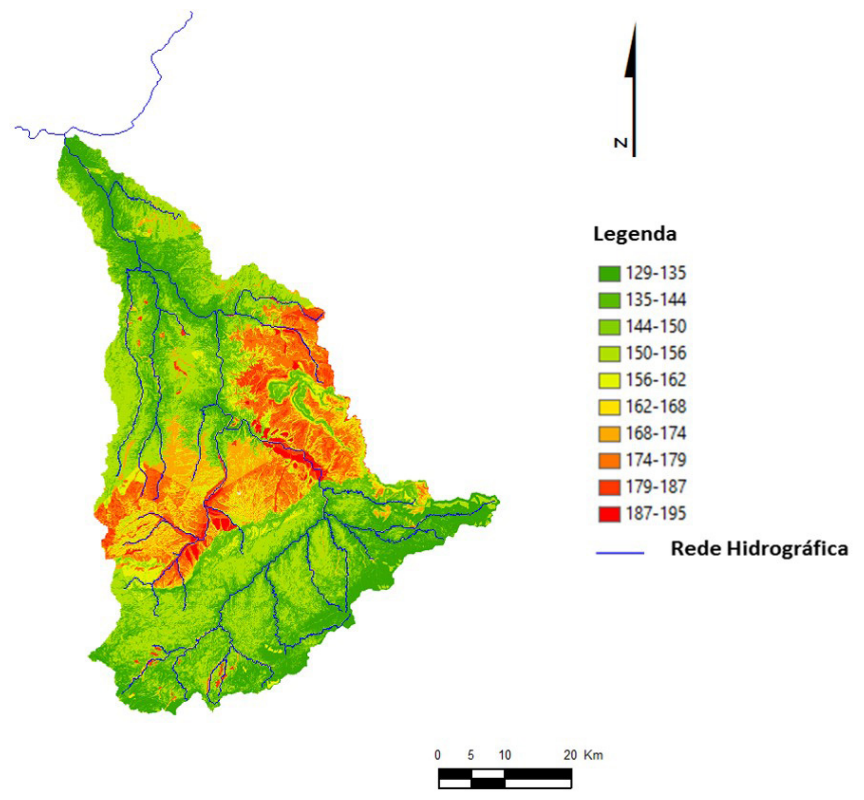

Fig. 2. Mapa do índice DRASTIC Pesticida na bacia hidrográfica do rio Águeda.

As zonas de vulnerabilidade moderada a elevada localizam-se, preferencialmente na zona central da bacia e coincidem com explorações mineiras de Sn-W e de U, com elevados teores de metais pesados associados e, também, com áreas de exploração agrícola massiva e criação de gado. A zona mais vulnerável corresponde ao extenso aquífero sedimentar terciário e área urbana e agrícola, desenvolvida na planície de Ciudad Rodrigo (Fig. 2).

\section{Construção de mapas estimados - Krigagem gaussiana}

A incorporação da estrutura espácio-temporal dos atributos em análise (cálcio e sulfatos), para a construção de cartografias estimadas, torna-se essencial na seleção das metodologias a adotar, onde a visualização da incerteza espacial associada à estimativa, permite uma análise crítica das representações obtidas.

A modelação geoestatística iniciou-se pelo estudo variográfico experimental, ao longo das principais direções e subsequente ajuste de modelo teórico, ao variograma experimental omnidirecional, uma vez que não foi possível modelar a anisotropia geométrica, para as duas variáveis. A krigagem gaussiana foi utilizada como interpolador otimizado, permitindo a 
atenuação dos valores extremos. O recurso ulterior à operação de transformação inversa, permitiu a representação dos resultados finais no real intervalo de valores da amostra (e.g. Albuquerque et al., 2013). No passo seguinte e recorrendo à utilização de um Sistema de Informação Geográfica (ArcMap 10, ESRI) foi possível construir mapas de distribuição de teores (Soares, 2006).

De um modo geral, a zona com os valores mais elevados para os parâmetros físico-químicos analisados coincide com a parte central da bacia hidrográfica (Ciudad Rodrigo).

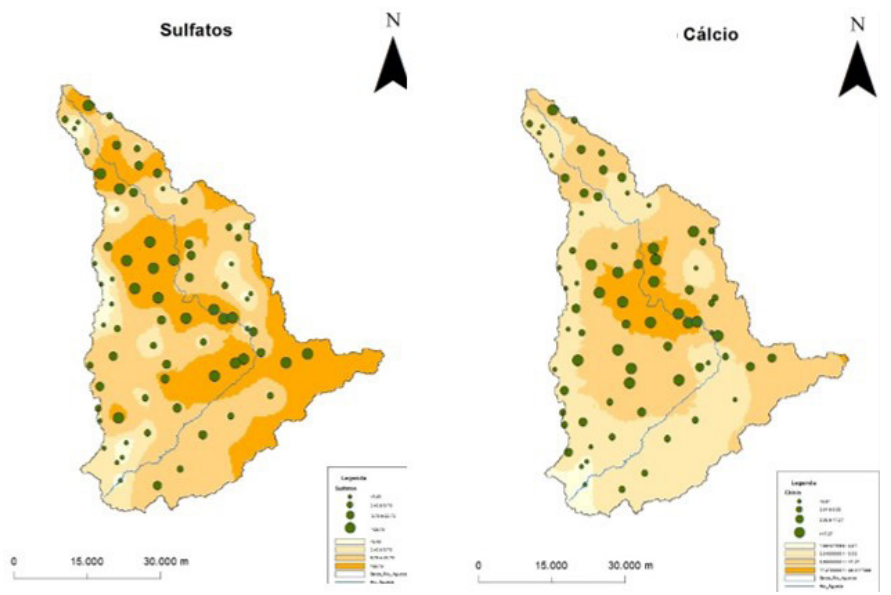

Figura 3. Mapas estimados para o cálcio e sulfatos na bacia hidrográfica do rio Águeda.

De destacar, a zona de vulnerabilidade intermédia a elevada, na parte norte da bacia, correspondendo a caraterísticas intrínsecas associadas à presença de calcários carsificados. Nesta área, as atividades humanas são reduzidas ou praticamente inexistentes (Fig. 2).

\section{Conclusão}

O presente trabalho permitiu estudar a distribuição espacial de diferentes parâmetros físicoquímicos na bacia hidrográfica do rio Águeda, com particular destaque para o cácio e sulfatos. Estes parâmetros indicam uma relação clara com as atividades antropogénicas, predominantemente agrícolas, concentradas na zona central da bacia hidrográfica e coincidindo com o extenso aquífero de materiais detríticos de idade Terciária (Ciudad Rodrigo). Esta zona corresponde à maior área urbana e industrial existente na bacia hidrográfica do rio Águeda.

A interpolação realizada por krigagem gaussiana, recorrendo ulteriormente à transformação inversa, permitiu, por um lado, atenuar o peso dos valores anómalos e, por outro, obter uma representação correspondente ao espaço original e, desta forma, construir mapas onde os valores estimados podem ser experimentalmente validados (Saito e Goovaerts, 2000). A validação dos resultados obtidos revelou-se adequada, e permitindo, desta forma, a definição de uma futura rede de monitorização específica e mais adequada.

\section{Bibliografia}

Albuquerque, M. T. D., Sanz, G., Oliveira, S.F., Martínez-Alegría, R., Antunes, I. M. H. R. (2013). SpatioTemporal Groundwater Vulnerability Assessment - A Coupled Remote Sensing and GIS Approach for 
Historical Land Cover Reconstruction. Water Resource Management 27, pp 4509-4526. DOI:10.1007/ s11269-013-0422-0; IF 2.259.

Aller, L., Bennet, T., Lehr, J.H., Petty, R.J., Hackett, G. (1987). DRASTIC: a standardized system for evaluating ground water pollution potential using hydrogeologic settings. U.S. Environmental Protection Agency (Eds.), EPA/600/2-87/035, Oklahoma, 641 pp.

Guerreiro, N., Pereira, P. B. (2002). Poluição e qualidade da água. Instituto da água/Direção de Serviços do Planeamento. Lisboa: Ministério das Cidades Ordenamento do território e ambiente.

ISA, (2013). Teoria de Amostragem [online]. Available from: http://www.isa. utl.pt/dm/mestrado/2009-10/ UCs/ta/seb_amost1.pdf [Accessed 25 october 2013].

Saito, H., Goovaerts, P. (2000). Geostatistical interpolation of positively skewed and censored data in a dioxin contaminated site. Environmental Science \& Technology, 34 (19): 4228-4235.

Sánchez-González, S., García-Sánchez, A., Caravantes, P., Rodríguez-Cruz, M. S., Sánchez-Martín, M. J. e Rodríguez, I.S.R. (2013). Caracterización y análisis de impactos ambientales en la cuenca del rio Águeda. In: Francisco Campos Sánchez-Bordona (Ed). Cuenca del rio Águeda un território para dos Países. Servicio de Publicaciones. Universidad Europea Miguel de Cervantes Valladolid, pp 35-64.

Soares, A. (2006). Geoestatística para as ciências da terra e do ambiente. $2^{\mathrm{a}}$ Ed. Lisboa: IST.

Scribd (2013). Análise de Riscos Ambientais e Lógica Fuzzy [online]. Available from: http://www.scribd.com/ doc/4809204/Analise-de-Riscos-Ambientais-e-Logica-Fuzzy [Accessed 28 october 2013] 